\title{
3D-to-2D Morphology Manipulation of Sputter-Deposited Nanoscale Silver Films on Weakly Interacting Substrates via Selective Nitrogen Deployment for Multifunctional Metal Contacts
}

Andreas Jamnig, Nikolaos Pliatsikas, Martin Konpan, Jun Lu, Thomas Kehagias, Alexios N. Kotanidis, Nikolaos Kalfagiannis, Dimitris V. Bellas, Elefterios Lidorikis, Janez Kovac, Gregory Abadias, Ivan Petrov, Joseph E. Greene, and Kostas Sarakinos*

Cite This: ACS Appl. Nano Mater. 2020, 3, 4728-4738

Read Online

ABSTRACT: The ability to reverse the inherent tendency of noble metals to grow in an uncontrolled three-dimensional (3D) fashion on weakly interacting substrates, including twodimensional (2D) materials and oxides, is essential for the fabrication of high-quality multifunctional metal contacts in key enabling devices. In this study, we show that this can be effectively achieved by deploying nitrogen $\left(\mathrm{N}_{2}\right)$ gas with high temporal precision during magnetron sputtering of nanoscale silver $(\mathrm{Ag})$ islands and layers on silicon dioxide $\left(\mathrm{SiO}_{2}\right)$ substrates. We employ real-time in situ film growth monitoring using spectroscopic ellipsometry, along with optical modeling in the framework of the finite-difference timedomain method, and establish that localized surface plasmon resonance (LSPR) from nanoscale $\mathrm{Ag}$ islands can be used to gauge the evolution of surface morphology of discontinuous layers up

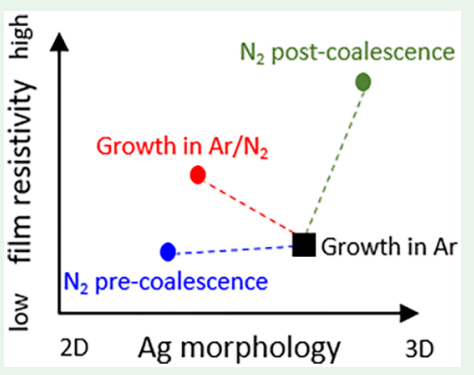
to a $\mathrm{SiO}_{2}$ substrate area coverage of $\sim 70 \%$. Such analysis, in combination with data on the evolution of room-temperature resistivity of electrically conductive layers, reveals that presence of $\mathrm{N}_{2}$ in the sputtering gas atmosphere throughout all film-formation stages: (i) promotes 2D growth and smooth film surfaces and (ii) leads to an increase of the continuous-layer electrical resistivity by $\sim 30 \%$ compared to $\mathrm{Ag}$ films grown in a pure argon (Ar) ambient atmosphere. Detailed ex situ nanoscale structural analyses suggest that $\mathrm{N}_{2}$ favors $2 \mathrm{D}$ morphology by suppressing island coalescence rates during initial growth stages, while it causes interruption of local epitaxial growth on $\mathrm{Ag}$ crystals. Using these insights, we deposit Ag layers by deploying $\mathrm{N}_{2}$ selectively, either during the early precoalescence growth stages or after coalescence completion. We show that early $\mathrm{N}_{2}$ deployment leads to $2 \mathrm{D}$ morphology without affecting the Ag-layer resistivity, while postcoalescence introduction of $\mathrm{N}_{2}$ in the gas atmosphere further promotes formation of three-dimensional (3D) nanostructures and roughness at the film growth front. In a broader context this study generates knowledge that is relevant for the development of (i) single-step growth manipulation strategies based on selective deployment of surfactant species and (ii) real-time methodologies for tracking film and nanostructure morphological evolution using LSPR.

KEYWORDS: silver, nitrogen, thin film, growth manipulation, FDTD calculations, in situ growth monitoring

\section{INTRODUCTION}

Vapor-based growth of thin noble-metal films with twodimensional (2D) morphology on weakly interacting 2D material and oxide substrates is essential for the fabrication of multifunctional metal contacts in a wide array of devices, including photodetectors, ${ }^{1,2}$ long-range surface plasmon resonance biosensors, ${ }^{3}$ and tunnel field-effect transistors for ultralight-weight mobile and wearable electronics. ${ }^{4,5}$ Noblemetal films typically exhibit a pronounced and uncontrolled three-dimensional (3D) morphology on weakly interacting substrates, ${ }^{4,6}$ which manifests itself by discontinuous layer formation during the initial film growth stages and rough surfaces upon formation of a continuous layer. From the viewpoint of thermodynamics, this growth behavior is explained by the fact that the adsorption energy of noblemetal atoms on weakly interacting surfaces is significantly smaller than the bulk metal binding energy, ${ }^{4,6}$ which provides the driving force for minimizing the metal/substrate contact area.

Film growth via vapor condensation is a far-fromequilibrium process, and hence, morphological evolution depends, primarily, on kinetic rates of atomic-scale structureforming mechanisms. ${ }^{7-10}$ The kinetic pathways leading to $3 \mathrm{D}$ morphologies in metal-on-metal homoepitaxial systems are well established in the literature. ${ }^{10}$ This understanding has

Received: March 16, 2020

Accepted: April 23, 2020

Published: April 23, 2020 
Scheme 1. Schematic Representation of the Vacuum Chamber Used for Magnetron-Sputter Deposition of Nanoscale Ag Islands and Continuous Layers on $\mathrm{SiO}_{2}$ Substrates ${ }^{a}$

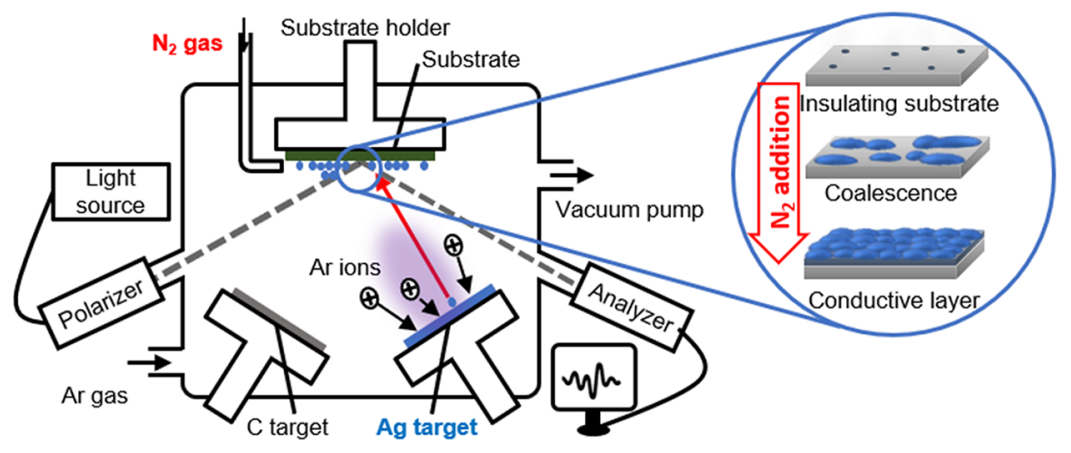

${ }^{a}$ The chamber is equipped with a spectroscopic ellipsometer for in situ and real-time monitoring of film growth. Nitrogen $\left(\mathrm{N}_{2}\right)$ is introduced to the sputtering atmosphere with high temporal precision to selectively target key film-formation stages and promote $2 \mathrm{D}$ growth morphology, without compromising the electrical conductivity of the Ag layers.

facilitated the development of growth manipulation strategies, in which minority metal ${ }^{11-17}$ and gaseous ${ }^{18,19}$ species (also termed surfactants) are deposited simultaneously with the filmforming species, thereby modifying atomic-scale kinetics and allowing navigation between $3 \mathrm{D}$ and $2 \mathrm{D}$ morphologies. Numerous studies on surfactant effects for semiconductor epitaxial film growth ${ }^{20-23}$ and metal-on-metal heteroepitaxial systems $^{24-26}$ are also available in the literature.

The mechanisms that govern morphological evolution of metal films on weakly interacting substrates are different than those in strongly interacting homo- and heteroepitaxial systems. $^{6,27-31}$ As a result, established knowledge for surfactant-based growth manipulation is not directly applicable to the case of noble-metal-film deposition on, e.g., oxides and 2D materials. Despite this, empirical studies exist in which lessnoble-metal surfactants and seed layers ${ }^{32-37}$ as well as gaseous surfactants (nitrogen $\left(\mathrm{N}_{2}\right)$ and oxygen $\left.\left(\mathrm{O}_{2}\right)\right)^{38-44}$ have been used to suppress $3 \mathrm{D}$ morphology of silver $(\mathrm{Ag})$ and copper $\mathrm{Cu})$ films on oxide substrates. The presence of surfactants at the film growth front, however, is often accompanied by changes in other physical properties of the noble-metal layers (e.g., electronic, optical, and transport properties), ${ }^{33,38,39}$ which, if not reversed or mitigated, render surfactant-based approaches largely inapplicable for metal-contact synthesis. Hence, a fundamental understanding of the surfactant effects on various film-growth stages (i.e., island nucleation, island growth, island coalescence, and hole filling) is required for designing knowledge-based, efficient, and noninvasive growth manipulation strategies.

In the present work, we investigate the effects of $\mathrm{N}_{2}$ on the growth of magnetron-sputtered nanoscale $\mathrm{Ag}$ islands and layers on silicon dioxide $\left(\mathrm{SiO}_{2}\right)$ substrates, with the purpose of exploring the viability of surfactant-based approaches for metal-contact fabrication, as conceptualized in Scheme 1. $\mathrm{Ag} / \mathrm{SiO}_{2}$ is an archetypal weakly interacting film/substrate system which exhibits pronounced $3 \mathrm{D}$ morphological evolution. ${ }^{4-48}$ Furthermore, $\mathrm{N}_{2}$ does not chemisorb on $\mathrm{Ag}$ surfaces, and no thermodynamically stable $\mathrm{Ag}-\mathrm{N}$ compounds exist, ${ }^{49}$ which enables us to focus on the effect of $\mathrm{N}_{2}$ on surface atomic-scale growth processes. By employing spectroscopic ellipsometry for real-time in situ film growth monitoring, along with finite-difference time-domain (FDTD) calculations, we show that addition of $\mathrm{N}_{2}$ to the sputtering gas atmosphere, throughout all film-growth stages, promotes in-plane nanoscale island growth and 2D film morphology, while it leads to an increase in the electrical resistivity of continuous layers, relative to Ag films grown in pure Ar. Moreover, we find-by means of detailed ex situ microstructural analyses-that 2D morphology is promoted because $\mathrm{N}_{2}$ suppresses the coalescence rate of nanoscale Ag islands, while the electrical resistivity increase is attributed to $\mathrm{N}_{2}$-induced grain refinement.

On the basis of the above insights highlighted in the previous paragraph, we design and implement a deposition protocol in which $\mathrm{N}_{2}$ is introduced during $\mathrm{Ag}$ film growth with high temporal precision for influencing selected film-formation stages. We show that when $\mathrm{N}_{2}$ is deployed only during island nucleation, growth, and coalescence, after which $\mathrm{N}_{2}$ supply is turned off, such that deposition commences in an $\mathrm{Ar} /$ $\mathrm{N}_{2}$ atmosphere and is completed in pure $\mathrm{Ar}$ atmosphere, 3D morphology is suppressed without compromising the Ag-layer electrical resistivity. In the opposite case, when deposition commences in an Ar atmosphere and $\mathrm{N}_{2}$ is introduced after island coalescence has been largely completed, the tendency for $3 \mathrm{D}$ morphological evolution is dramatically enhanced. The overall results of this study provide the scientific foundation for designing advanced growth manipulation strategies based on selective deposition of surfactants to promote $2 \mathrm{D}$ growth without affecting the film physical properties. Such approaches can also be the basis of single-step room-temperature processes for enhancing 3D morphology and tuning the size of supported nanoparticles. Moreover, the combination of FDTD calculations and experiments highlights a path toward real-time methodologies for tracking metal film and nanostructure morphological evolution by using LSPR.

\section{RESEARCH METHODOLOGY}

2.1. Film Growth. Ag films are grown by direct-current magnetron sputtering (dcMS), at a constant current mode of $20 \mathrm{~mA}$, on $\mathrm{Si}(001)$ substrates with an $\sim 530 \mathrm{~nm}$ thick thermally grown $\mathrm{SiO}_{2}$ overlayer. No intentional heating is applied on the substrate, and all depositions are performed in a multisource, ultrahigh-vacuum (UHV) chamber with a base pressure below $10^{-10}$ Torr $\left(\sim 10^{-8} \mathrm{~Pa}\right)$. The Ag target (purity 99.99 at. \%; diameter $7.6 \mathrm{~cm}$; thickness $6 \mathrm{~mm}$ ) is placed $7.5 \mathrm{~cm}$ away from the substrate and at a $45^{\circ}$ angle with respect to the substrate surface normal.

$\mathrm{Ag}$ depositions are performed in $\mathrm{Ar}$ and $\mathrm{Ar} / \mathrm{N}_{2}$ mixtures at a total working pressure $p_{\text {total }}$ of $10 \mathrm{mTorr}(1.33 \mathrm{~Pa})$. For 
samples grown in $\mathrm{Ar} / \mathrm{N}_{2}$ atmospheres, initial tests at various $\mathrm{N}_{2}$ partial pressures $p_{\mathrm{N} 2}$ showed that increasing $p_{\mathrm{N} 2}$ from $0.05 p_{\text {total }}$ to $0.1 p_{\text {total }}$ affected film growth (as evidenced from in situ ellipsometry data by using the methodologies described in section 2.2), while no appreciable difference was observed for further $p_{\mathrm{N} 2}$ increase up to $0.15 p_{\text {total }}$. Hence, on the basis of results of those initial tests, in this article we focus on experiments performed at $p_{\mathrm{N} 2}=0.1 p_{\text {total }}$. It should be pointed out that additional effects on film properties for $p_{\mathrm{N} 2}$ values well outside the range considered here (i.e., substantially larger than $\left.0.15 p_{\text {total }}\right)$ cannot be ruled out; see for example the studies by Lee et al. ${ }^{50}$ and Wang et al. ${ }^{51}$ on the growth of $\mathrm{Cu}-\mathrm{O}$ films in $\mathrm{Ar}-\mathrm{O}_{2}-\mathrm{N}_{2}$ gas mixtures, in which it was found that $\mathrm{N}_{2}$ partial pressures above $\sim 30 \%$ of the total working pressure affect profoundly the plasma chemistry and film electron transport properties.

Film morphological evolution, microstructure, and chemical composition are analyzed by using the in situ and $e x$ situ tools and methodologies described in sections 2.2 and 2.3, respectively. Prior to exposing the samples to atmosphere for ex situ analyses, and immediately after Ag deposition, samples are capped with a $3 \mathrm{~nm}$ thick amorphous carbon (a-C) layer to avoid surface contamination and changes in film morphology upon atmospheric exposure. The a-C capping layers are sputter-deposited at a rate of $0.01 \mathrm{~nm} / \mathrm{s}$ in the same UHV chamber from a graphite target (purity 99.99 at. \%; diameter $7.6 \mathrm{~cm}$; thickness $6 \mathrm{~mm}$ ) in pure Ar discharge at $10 \mathrm{mTorr}$. The graphite target is operated with dcMS at a constant current mode of $50 \mathrm{~mA}, 7.5 \mathrm{~cm}$ away from the substrate, and at an angle of $45^{\circ}$ with the substrate surface normal.

2.2. In Situ Film Growth Monitoring. Spectroscopic ellipsometry is employed to monitor the change in film optoelectronic properties during deposition and, thereby, provide real-time insights into film morphological evolution. Ellipsometric angles $\Psi$ and $\Delta$ are acquired every $\sim 2$ s at 67 incident-light photon energies in the range $1.6-3.2 \mathrm{eV}$, at an angle of incidence of $\sim 70^{\circ}$ from the substrate normal, by using a J.A. Woollam Inc. M-88 instrument. The acquired data are fitted to a three-phase model consisting of substrate, film, and vacuum. The substrate is modeled as a $625 \mu \mathrm{m}$ thick Si slab with a $\mathrm{SiO}_{2}$ overlayer, the thickness of which $(\sim 530 \mathrm{~nm})$ is confirmed by measuring the optical response of the substrate prior to deposition. Reference data for the substrate layers are taken from Herzinger et al. ${ }^{52}$ The optical response of the film is described by different dispersion models, depending on the film growth stage (i.e., nominal film thickness $\Theta$ ), as detailed below.

During initial growth stages, the film surface primarily features isolated $\mathrm{Ag}$ islands that support LSPR. ${ }^{46,53}$ Being a resonant effect, LSPR can be described by adapting the Lorentz oscillator model ${ }^{46,53}$ to express the complex dielectric function of the layer $\tilde{\epsilon}(\omega)$ as

$$
\tilde{\epsilon}(\omega)=\frac{f \omega^{2}}{\omega_{0}{ }^{2}-\omega^{2}-i \Gamma \omega}
$$

In eq $1, f$ and $\omega_{0}$ are the oscillator strength and resonance frequency, respectively, and $\Gamma$ represents the damping rate of the plasmon resonance. It should be emphasized here that eq 1 describes the effective LSPR of the nanoscale Ag islands/air complex system, which is considered a homogeneous layer. Moreover, the single Lorentz model does not account for dipole-dipole interactions; i.e., the optical response of early growth-stage $\mathrm{Ag}$ layers can be accurately modeled by eq 1 as long as the distance between islands is large enough to render island-island interactions ineffective. ${ }^{46,53}$

The optical response of electrically conductive $\mathrm{Ag}$ films is described by the Drude free electron theory, which is extensively used for ideal metals. ${ }^{54}$ In this case, $\tilde{\epsilon}_{\mathrm{D}}(\omega)$ is given by the expression

$$
\tilde{\epsilon}_{\mathrm{D}}(\omega)=\epsilon_{\infty}-\frac{\omega_{\mathrm{p}}{ }^{2}}{\omega^{2}+i \Gamma_{\mathrm{D}} \omega}
$$

In eq $2, \epsilon_{\infty}$ is a constant that accounts for the effect of interband transitions occurring at frequencies higher than the ones considered here, $\Gamma_{\mathrm{D}}$ is the free-electron damping constant, and $\omega_{\mathrm{p}}=\sqrt{n e^{2} / \varepsilon_{0} m_{\mathrm{e}}}$ is the free-electron plasma frequency, where $n$ is the free-electron density, $\varepsilon_{0}$ is the permittivity of free space, and $m_{\mathrm{e}}$ is the free-electron effective mass. From eq 2, the room-temperature film resistivity is calculated as ${ }^{54}$

$$
\rho=\frac{\Gamma_{\mathrm{D}}}{\epsilon_{0} \omega_{\mathrm{p}}^{2}}
$$

In addition to optical properties, analysis of the ellipsometric data provides the film thickness $h_{\mathrm{f}}$ as a function of deposition time $t$. Based upon $h_{\mathrm{f}}$ values of continuous layers, a deposition rate $F \cong 0.1 \mathrm{~nm} / \mathrm{s}$ is obtained, irrespective of the growth conditions. This allows the nominal film thickness, $\Theta=F \times t$, to be determined to be a function of the deposition time. Here, $\Theta$ is expressed in monolayers (ML), in which $1 \mathrm{ML}$ corresponds to the distance between adjacent $\mathrm{Ag}(111)$ atomic planes $(0.236 \mathrm{~nm})$. We note that $h_{\mathrm{f}}$ is also determined by $e x$ situ X-ray reflectometry measurements, as detailed in section 2.3.

2.3. Ex Situ Characterization. Crystal structure, coherence length, and film texture are determined by X-ray diffractometry (XRD) in Bragg-Brentano geometry by using a Panalytical X'pert Pro diffractometer. Film thickness, density, and roughness are determined by X-ray reflectometry (XRR), performed in a Panalytical Empyrean diffractometer. For both techniques, a copper $\mathrm{K} \alpha$ source (wavelength $0.15418 \mathrm{~nm}$ ) in line focus is used (operated with $45 \mathrm{kV}$ and $40 \mathrm{~mA}$ ), with a parallel beam mirror and parallel plate collimator in incident and diffracted/reflected beam path, respectively. The diffracted/reflected X-ray signal is processed with a X'Celerator/ PIXcel-3D detector (Malvern Pananalytical) operated in scanning line mode. Moreover, a nickel filter is used in XRD measurements for removing the copper $\mathrm{K} \beta$ radiation.

Film morphology during initial growth stages is analyzed by plan-view transmission electron microscopy (TEM) as a function of nominal film thickness $\Theta$. Plan-view specimens are prepared by depositing a-C-capped $\mathrm{Ag}$ films, grown in both $\mathrm{Ar}$ and $\mathrm{Ar} / \mathrm{N}_{2}$ atmospheres, on electron-transparent $\mathrm{SiO}_{2}$ grids, stabilized by a Formvar foil. The TEM specimens are imaged in bright- and dark-field modes by using a FEI G2 TF20UT transmission electron microscope operated at $200 \mathrm{kV}$ with 0.19 $\mathrm{nm}$ resolution. Selected area electron diffraction (SAED) patterns are also recorded to obtain information about the film crystal structure.

The microstructure and growth morphology of Ar- and Ar/ $\mathrm{N}_{2}$-grown continuous $\mathrm{Ag}$ layers are examined by crosssectional TEM (XTEM). Specimens are prepared by mechanical polishing, followed by $\mathrm{Ar}^{+}$ion milling in a Gatan 
PIPS TEM; high-resolution TEM (HRTEM) and SAED data are acquired in a Jeol 2011 UHR electron microscope, operated at $200 \mathrm{kV}$, with a point resolution of $0.194 \mathrm{~nm}$ and a spherical aberration of $0.5 \mathrm{~mm}$.

Film chemical composition is determined by X-ray photoelectron spectroscopy (XPS). XPS measurements are performed in a Kratos AXIS Ultra DLD UHV system (base pressure $\sim 3 \times 10^{-10}$ Torr), equipped with a monochromated aluminum $\mathrm{K} \alpha \mathrm{X}$-ray beam, a hemispherical sector analyzer, and a multichannel detector. A $20 \mathrm{eV}$ pass energy, resulting in full width at half-maximum (FWHM) of $<500 \mathrm{meV}$ for the $\mathrm{Ag}$ $3 \mathrm{~d}_{5 / 2}$ peak, is used to record core-level spectra. Measurements are performed as a function of the sample depth by etching the surface with a $4 \mathrm{keV} \mathrm{Ar}^{+}$ion beam. Charge-induced shifts of the binding energy are corrected with respect to the Ar- $2 p$ peak, which originates from Ar implanted in the film during the $\mathrm{Ar}^{+}$ion sputtering process. The Kratos Vision software and its sensitivity factor database are used for elemental analysis.

Compositional depth profiles are also acquired using timeof-flight secondary ion-mass spectrometry (ToF-SIMS) in a ToF.SIMS 5 instrument (ION-TOF; Münster, Germany) with a base pressure of $7.5 \times 10^{-10}$ Torr. A $1 \mathrm{keV}$ cesium ion $\left(\mathrm{Cs}^{+}\right)$ beam produces a $400 \times 400 \mu \mathrm{m}^{2}$ crater at a rate of $\sim 0.3 \mathrm{~nm} / \mathrm{s}$. SIMS spectra are acquired while scanning a 1 pA $30 \mathrm{keV}$ bismuth ion $\left(\mathrm{Bi}^{+}\right)$beam over sample areas of $100 \times 100 \mu \mathrm{m}^{2}$. SIMS spectra are recorded every $1 \mathrm{~s}$.

2.4. Finite-Difference Time-Domain Calculations. Along with the ellipsometric analyses, we perform optical calculations based on the finite-difference time-domain (FDTD) method ${ }^{55,56}$ to evaluate the LSPR positions and compare them with the experimentally determined Lorentzoscillator energy $\left(\hbar \omega_{0}\right)$ values (see eq 1$)$. We use surface morphology data (i.e., island size and number density) obtained from ex situ plan-view TEM measurements (see section 2.3 for details) to compute the total reflectivity of the nanoscale $\mathrm{Ag}$ islands in the near-infrared, visible, and ultraviolet spectral range and thereby extract the LSPR position from the maximum of the corresponding spectra reflectivity curves. More information about the use of planview TEM data for FDTD calculations is given in the Supporting Information.

\section{RESULTS AND DISCUSSION}

3.1. Film Morphological Evolution. The room-temperature resistivities of percolated $\mathrm{Ag}$ films grown in pure $\mathrm{Ar}$ and $\mathrm{Ar} / \mathrm{N}_{2}$ mixtures are plotted in Figure 1 as a function of the nominal thickness $\Theta$. The data are extracted from in situ spectroscopic ellipsometry analysis, as explained in section 2.2. Both $\rho$ vs $\Theta$ curves exhibit a sharp initial drop until they reach a steady-state value $\rho^{\text {ss }}$. We have previously shown ${ }^{57}$ that the $\Theta$ value at which $\rho^{\text {ss }}$ is established marks the completion of the hole-filling process and the formation of a continuous film. The data in Figure 1 show that addition of $\mathrm{N}_{2}$ in the growth atmosphere results in the thickness of continuous film formation $\Theta_{\text {cont }}$ to decrease to $51 \mathrm{ML}$ from $78 \mathrm{ML}$ for the $\mathrm{Ag}$ film grown in pure Ar. Thus, the presence of $\mathrm{N}_{2}$ promotes $2 \mathrm{D}$ growth. Furthermore, $\mathrm{Ag}$ growth in $\mathrm{N}_{2}$-containing atmosphere yields a steady-state resistivity $\rho^{\mathrm{ss}}=1.4 \times 10^{-5}$ $\Omega \cdot \mathrm{cm}$, which is larger than the corresponding value $1.1 \times 10^{-5}$ $\Omega \cdot \mathrm{cm}$ for films grown in pure Ar.

To correlate early film growth stages with the morphological evolution trends extracted from Figure 1, we perform plan-view $\mathrm{TEM}$ investigations for a-C/Ag/ $\mathrm{SiO}_{2}$ samples grown in $\mathrm{Ar}$ and

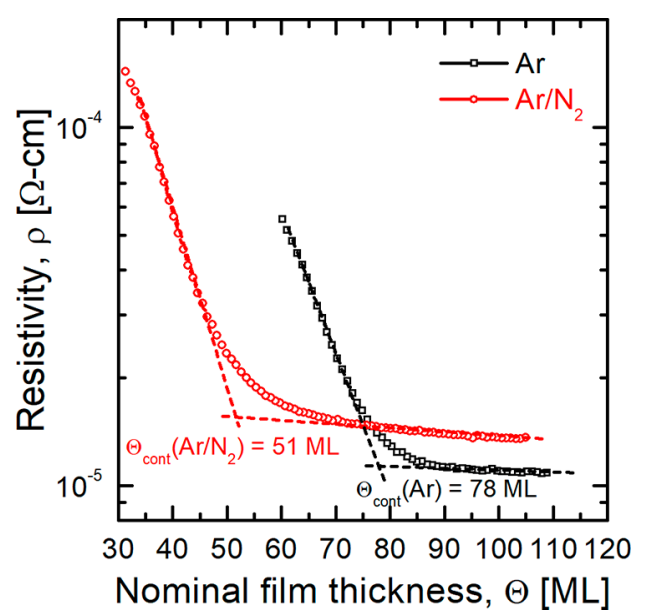

Figure 1. Resistivity $(\rho)$ vs nominal thickness $(\Theta)$ curves extracted from in situ, real-time spectroscopic ellipsometry measurements (see section 2.2) of magnetron sputter-deposited $\mathrm{Ag}$ layers on $\mathrm{SiO}_{2} / \mathrm{Si}$ substrates in $\mathrm{Ar}$ (hollow black squares) and $\mathrm{Ar} / \mathrm{N}_{2}$ (hollow red circles) atmospheres. The nominal thickness $\Theta_{\text {cont }}$ at which the film becomes continuous is 51 and $78 \mathrm{ML}$ for films grown in $\mathrm{Ar} / \mathrm{N}_{2}$ and pure Ar, respectively.

$\mathrm{Ar} / \mathrm{N}_{2}$ atmospheres. Typical micrographs, for $\Theta=2,8,21$, and $42 \mathrm{ML}$, are displayed in Figure 2 (top and bottom panel for Ar-

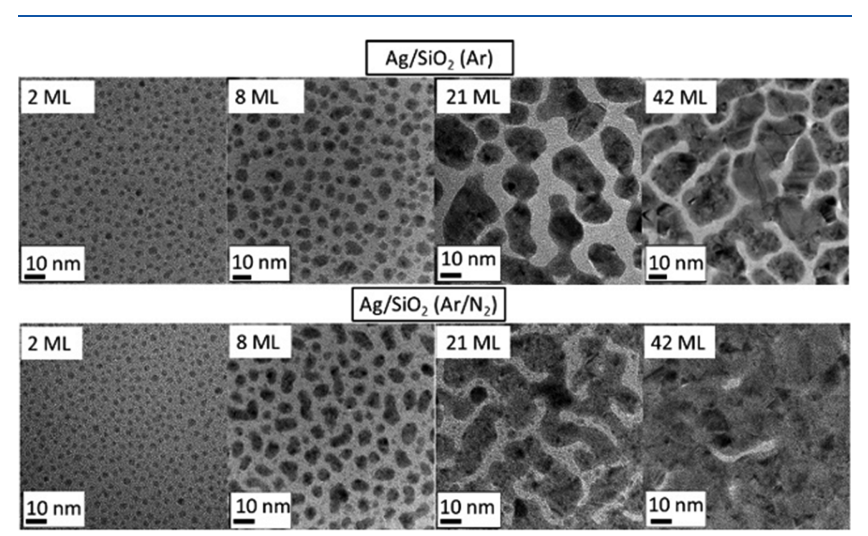

Figure 2. Typical bright-field plan-view TEM micrographs of discontinuous magnetron sputter-deposited $\mathrm{Ag}$ films on $\mathrm{SiO}_{2} / \mathrm{Si}$ substrates in $\mathrm{Ar}$ (top row) and $\mathrm{Ar} / \mathrm{N}_{2}$ (bottom row) atmospheres at nominal thicknesses $\Theta=2,8,21$, and $42 \mathrm{ML}$.

and $\mathrm{Ar} / \mathrm{N}_{2}$-grown samples, respectively). Irrespective of the composition of the sputtering gas atmosphere, the plan-view TEM data show the expected overall film morphological evolution as a function of $\Theta$ : the initially formed isolated nanoscale islands increase in size, until they start impinging upon another, and coalesce. Further vapor deposition leads to island sizes that hinder coalescence completion, which results in the formation of an interconnected island network and eventually (for the film grown in $\mathrm{Ar} / \mathrm{N}_{2}$ atmosphere at $\Theta=42$ $\mathrm{ML})$ in a nearly continuous layer.

For $\Theta=2 \mathrm{ML}$, both $\mathrm{Ar}$ - and $\mathrm{Ar} / \mathrm{N}_{2}$-grown film surfaces feature nearly spherical islands with sizes in the range $\sim 1-2$ $\mathrm{nm}$. Moreover, the presence of $\mathrm{N}_{2}$ in the growth atmosphere results in a slight increase of the island number density. By analyzing data from multiple images, we find island densities of $(3.97 \pm 0.45) \times 10^{16}$ and $(4.13 \pm 0.40) \times 10^{16} \mathrm{~m}^{-2}$ for films deposited in $\mathrm{Ar}$ and $\mathrm{Ar} / \mathrm{N}_{2}$ atmospheres, respectively. This change by only $\sim 5 \%$ is rather marginal, relative to multifold 
increases in homoepitaxial growth experiments performed at the presence of surfactant gases. ${ }^{10,18}$ Hence, we conclude that $\mathrm{N}_{2}$, at the partial pressures used in this study, does not have a significant effect on $\mathrm{Ag}$ adspecies surface diffusion rates during nucleation and early film-growth stages.

More pronounced differences in the film morphology are observed at larger nominal thicknesses. For $\Theta=8 \mathrm{ML}$, deposition in Ar atmosphere yields mostly spherical islands with sizes between $\sim 2$ and $\sim 7 \mathrm{~nm}$. Addition of $\mathrm{N}_{2}$ leads, instead, to a film surface that hosts, predominantly, polycrystalline elongated island clusters with sizes $\sim 5-10 \mathrm{~nm}$. Experimental and theoretical studies on the growth of metals on weakly interacting substrates ${ }^{45,58-61}$ have attributed the formation of elongated cluster shapes to a decrease in the rate of island coalescence. On the basis of these studies, we conclude that the presence of $\mathrm{N}_{2}$ in the gas atmosphere causes suppression of coalescence-induced cluster reshaping, promoting in-plane island growth and 2D growth morphology. In a recent study of vapor-based growth of $\mathrm{Ag}$ nanoparticles on $\mathrm{ZnO}$ in $\mathrm{Ar} / \mathrm{N}_{2}$ gas mixtures, Yun et al. ${ }^{44}$ suggested that atomic nitrogen incorporation onto nanoparticle facets lowers their surface energy and thereby the thermodynamic driving force for coalescence. This mechanism may also be relevant for explaining the results in Figure 2, but further research is required to understand the atomistic pathways by which $\mathrm{N}_{2}$ suppresses the coalescence rate of nanoscale Ag islands.

At a nominal thickness $\Theta=21 \mathrm{ML}$, the plan-view TEM micrograph that corresponds to the Ar-grown sample shows the existence of isolated island clusters at various stages of coalescence, which cover $\sim 60 \%$ of the substrate surface. For the same amount of deposited material, the $\mathrm{Ar} / \mathrm{N}_{2}$-grown sample surface consists of interconnected islands and the substrate area coverage is $\sim 70 \%$. Moreover, the presence of $\mathrm{N}_{2}$ causes the appearance of smaller islands, with sizes $\sim 1 \mathrm{~nm}$, both in between and on the top of the elongated $\mathrm{Ag}$ clusters. The existence of these small islands is a signature of repeated nucleation, i.e., interruption of local epitaxial growth and nucleation of new islands with different crystallographic orientation. ${ }^{9,27}$

An almost continuous film with only a small fraction of the substrate surface exposed is obtained at $\Theta=42 \mathrm{ML}$, when deposition is performed in an $\mathrm{Ar} / \mathrm{N}_{2}$ atmosphere. In contrast, the Ag layer is still discontinuous (substrate area coverage $\sim 80 \%$ ) in pure Ar atmosphere for the same nominal thickness. The overall results presented in Figure 2 are qualitatively consistent and confirm the trends observed in Figure 1, i.e., $\mathrm{N}_{2}$ addition to the growth atmosphere promotes $2 \mathrm{D}$ film morphological evolution.

Discontinuous Ag layers that consist of isolated islands and/ or island clusters, i.e., films for $\Theta \leq 21 \mathrm{ML}$ according to the results presented in Figure 2, can give rise to LSPR. ${ }^{46,49}$ Using data from multiple images (like those presented in Figure 2) as input, we performed FDTD calculations and estimated the expected LSPR energies for $\mathrm{Ar}$ - and $\mathrm{Ar} / \mathrm{N}_{2}$-grown films, as explained in section 2.4 and in the Supporting Information. Representative experimental (TEM) and simulated plan-view morphologies along with the corresponding calculated reflectivity spectra for $\Theta=2 \mathrm{ML}$ (film deposited in $\mathrm{Ar}$ atmosphere) are displayed in Figures $3 a, 3 b$, and $3 c$, respectively. Additional data for $\mathrm{Ar}$ - and $\mathrm{Ar} / \mathrm{N}_{2}$-grown films at $\Theta=2$ and $8 \mathrm{ML}$ are presented in the Supporting Information. The theoretical LSPR position corresponds to the

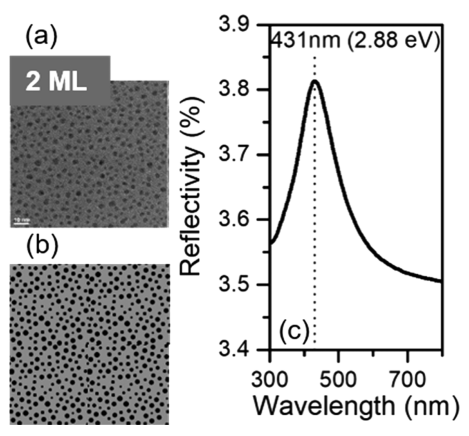

Figure 3. (a) Plan-view TEM image $\left(105 \times 105 \mathrm{~nm}^{2}\right)$, (b) simulated random $\mathrm{Ag}$ island distribution, and (c) calculated reflectivity spectrum for an Ar-grown Ag film at $\Theta=2 \mathrm{ML}$. The vertical dotted line in (c) marks the wavelength at which the maximum of the reflectivity curve occurs and corresponds to the theoretical LSPR position.

wavelength at which the reflectivity curve exhibits its maximum value, as marked by the vertical dotted line in Figure 3c.

Figure 4a presents the FDTD-predicted LSPR position (full symbols) along with the Lorentz-model resonance energy $\hbar \omega_{0}$
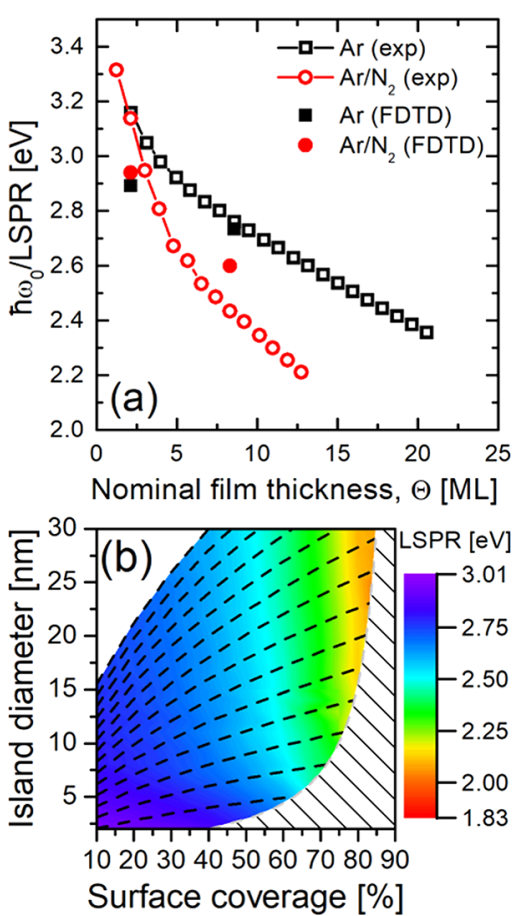

Figure 4. (a) Lorentz resonance energy $\hbar \omega_{0}$ (hollow symbols; extracted from in situ, real-time spectroscopic ellipsometry) and calculated LSPR (full symbols; obtained using the finite difference time-domain method) vs nominal thickness $(\Theta)$ of discontinuous magnetron-sputter-deposited $\mathrm{Ag}$ layers on $\mathrm{SiO}_{2} / \mathrm{Si}$ substrates in pure $\mathrm{Ar}$ (squares) and $\mathrm{Ar} / \mathrm{N}_{2}$ (circles) atmospheres. (b) Color-coded map of FDTD-calculated LSPR position of hemispherical periodic island arrays of various substrate coverages and island diameters. The black dashed lines indicate the iso-population point of the size-coverage parameter space.

(hollow symbols), obtained from in situ ellipsometric analyses, as a function of $\Theta$. Irrespective of the composition of the sputtering atmosphere, both calculated and experimentally obtained resonance energy values exhibit qualitatively consistent trends vs $\Theta$ (i.e., red-shift), while they are in fairly good quantitative agreement. This agreement confirms that the 

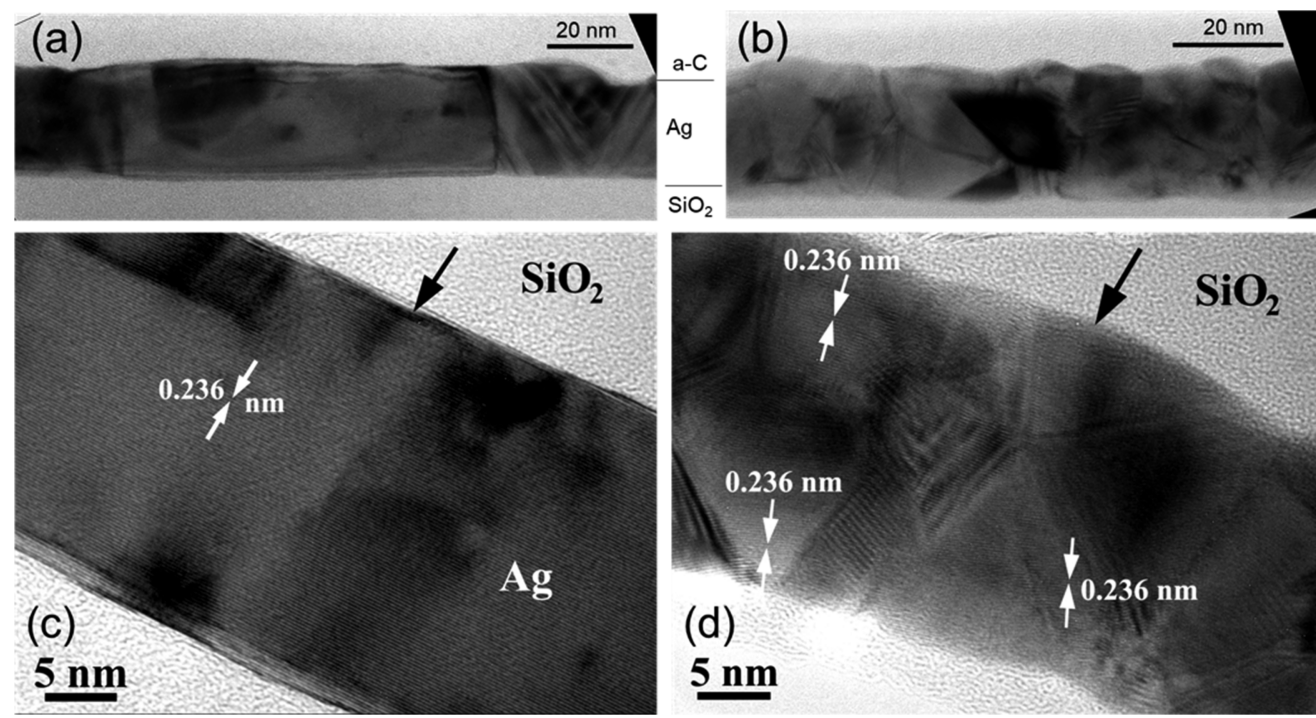

Figure 5. Cross-sectional TEM (XTEM) micrographs of continuous magnetron-sputter-deposited $\mathrm{Ag}$ films on $\mathrm{SiO} / 2 \mathrm{Si}$ in $(\mathrm{a}) \mathrm{Ar}$ and (b) $\mathrm{Ar} / \mathrm{N}_{2}$ atmospheres. Panels $\mathrm{c}$ and d display corresponding HRTEM images from panels a and b, illustrating a (111)-oriented large crystal in the Ar-grown $\mathrm{Ag}$ film and multiple twinned grains in $\mathrm{Ar} / \mathrm{N}_{2}$-grown Ag film, respectively. Moiré fringes arise due to overlapping of slightly disoriented adjacent Ag grains. In both images, the $0.236 \mathrm{~nm}$ interplanar spacing of the (111) planes and the growth direction are denoted by the white and black arrows, respectively.

Lorentz model is an accurate description of the effective resonant response of the nanoscale $\mathrm{Ag}$ islands on the surface of the substrate during the initial film-growth stages.

Upon vapor deposition up to $\sim 2 \mathrm{ML}$, the $\mathrm{LSPR} / \hbar \omega_{0}$ vs $\Theta$ curves for both $\mathrm{Ar}$ - and $\mathrm{Ar} / \mathrm{N}_{2}$-grown films are essentially identical, indicating no significant difference in the film morphology, which is consistent with plan-view TEM results for $\Theta=2 \mathrm{ML}$ in Figure 2. The systematic shift of the FDTDcalculated LSPR positions to lower values relative to the ellipsometry-derived $\hbar \omega_{0}$ at $\Theta=2 \mathrm{ML}$ can be attributed to (i) the use of a correction factor to the electron scattering time in the FDTD calculations (see the Supporting Information), which may successfully capture the major effects of plasmon damping, but overestimates the plasmon broadening and underestimates the plasmon blue-shift; ${ }^{62-64}$ (ii) the fact that classical electromagnetism, used in FDTD, cannot account for nonlocalities, including blue-shift and quenching of the plasmon resonance of very small particle sizes; ${ }^{62-64}$ and (iii) the low sample reflectivity at the initial growth stages (i.e., small $\Theta$ values).

For $\Theta>2 \mathrm{ML}, \mathrm{N}_{2}$ addition to the sputtering atmosphere leads to a steeper decline of the $\mathrm{LSPR} / \hbar \omega_{0}$ vs $\Theta$ curve compared to the Ar-deposited film. The red-shift in the LSPR/ $\hbar \omega_{0}$ position has been attributed in the literature to changes in island size and/or in inter-island separation; ${ }^{46,53}$ i.e., it reflects changes of surface areal coverage with continued deposition. To better understand the correlation among the data in Figure 4a and early stage film morphological evolution, we calculate (using FDTD) the LSPR positions for various periodic and close-packed hemispherical island arrays as a function of the substrate surface coverage (in the range 10 to 90\%) for two scenarios: (i) the island number density (i.e., number of islands $/ \mathrm{m}^{2}$ ) is kept constant, and the surface coverage is varied by changing the island volume (i.e., diameter); (ii) the island diameter is kept constant, and the surface coverage is varied by changing the island number density. The results of these calculations are shown in Figure 4b, whereby the contour plot is a color-coded map which depicts the LSPR evolution for the scenarios $\mathrm{i}$ and ii above. The island iso-population points are indicated by black dashed lines, while the gray-line-shaded region denotes surfaces on which islands are separated by $<1$ $\mathrm{nm}$, and other nonlocal effects make the FDTD calculations inaccurate $^{64}$ (more details on the calculations can be found in the Supporting Information). From the data in Figure $4 b$, it becomes evident that an LSPR red-shift of a magnitude that is consistent with the experimental results in Figure 4a requires a significant increase of the areal coverage that is caused by a concurrent increase/decrease of island size/island-island separation. Hence, the steeper $\mathrm{LSPR} / \hbar \omega_{0}$ vs $\Theta$ curve slope for the $\mathrm{Ar} / \mathrm{N}_{2}$ grown sample (relative to the Ar-deposited one) indicates that the presence of $\mathrm{N}_{2}$ promotes in-plane vs out-ofplane island growth, in agreement with the morphology evidenced by the plan-view TEM data for $\Theta=8$ and $21 \mathrm{ML}$ in Figure 2. Moreover, by combining the results in Figures 1-4a, we conclude that film morphological evolution, as manifested by changes in $\Theta_{\text {cont }}$ at later growth stages, is largely set during the initial film-formation stages of island growth and coalescence.

\subsection{Continuous Film Microstructure and Structure-} Forming Process. The effect of adding $\mathrm{N}_{2}$ to the sputtering atmosphere on the microstructure and chemical composition of continuous layers is also investigated. XRD analyses for $\sim 25$ $\mathrm{nm}$ thick Ar- and $\mathrm{Ar} / \mathrm{N}_{2}$-grown Ag samples are presented in Figure S4. The XRD pattern of the Ag film grown in pure Ar atmosphere shows 111 preferred orientation with a full width at half-maximum (FWHM) of $0.44^{\circ}$. The XRD pattern of the $\mathrm{Ar} / \mathrm{N}_{2}$-deposited layer exhibits no indication of strong texture formation, a much lower (111) peak intensity, and a wider FWHM of $0.88^{\circ}$. The latter is an indication that presence of $\mathrm{N}_{2}$ causes the formation of a finer grain structure compared to films deposited in pure Ar.

Typical XTEM micrographs for $\mathrm{Ar}$ - and $\mathrm{Ar} / \mathrm{N}_{2}$-grown samples are shown in Figures $5 a$ and $5 b$, respectively. The micrograph of the Ag layer grown in a pure Ar atmosphere (Figure 5a) reveals a microstructure composed of columnar grains with in-plane sizes up to $100 \mathrm{~nm}$, which extend 
throughout the entire film growth direction. The projected film thickness, obtained from multiple positions, is found to be 27.5 $\pm 1.8 \mathrm{~nm}$, and no discontinuities are observed, which is consistent with data in Figure 1 showing that a continuous layer is obtained at $78 \mathrm{ML}(\sim 18 \mathrm{~nm})$. The absence of discontinuities is also the case for the film grown in an $\mathrm{Ar} / \mathrm{N}_{2}$ atmosphere (Figure $5 \mathrm{~b}$ ). However, the grains of the $\mathrm{Ar} / \mathrm{N}_{2}$ deposited layer have more globular shapes and smaller sizes in the range $10-20 \mathrm{~nm}$, and they are irregularly stacked along the growth direction. This morphology yields a similar to the Argrown layer mean projected thickness of $26.8 \mathrm{~nm}$, but a larger statistical spread of $\pm 3.6 \mathrm{~nm}$.

The polycrystalline nature of both $\mathrm{Ar}$ - and $\mathrm{Ar} / \mathrm{N}_{2}$-grown films, evidenced by the XRD data in Figure S4, is also confirmed by the ring-type SAED patterns presented in Figure S5. Moreover, the SAED patterns-recorded under the same size selected area aperture - reveal an apparently lower number of reflections in the Ar-grown Ag film, which indicates the occurrence of larger Ag crystals compared to the film deposited in $\mathrm{Ar} / \mathrm{N}_{2}$ gas mixtures. Concerning preferred growth orientation, HRTEM imaging shows that large Ag grains in Ar-grown films are $\langle 111\rangle$ oriented; namely, their $\{111\}$ crystal planes are normal to the [100] growth direction of the Si substrate (Figure 5c). This crystallographic texture becomes considerably less pronounced for $\mathrm{Ar} / \mathrm{N}_{2}$-grown films because of the random orientation of the smaller $\mathrm{Ag}$ crystals (Figure $5 \mathrm{~d})$, which is consistent with XRD analysis.

XPS analyses of Ar- and $\mathrm{Ar} / \mathrm{N}_{2}$-grown films, after sputteretching $\sim 3 \mathrm{~nm}$ of surface layers (see Figure S6 for spectra), show the existence of all Ag-related peaks (Ag-3s, Ag-3p, Ag3d, Ag-4s, and Ag-4p). In addition, Ag-3d core-level highresolution scans (also presented in Figure S6) reveal that only $\mathrm{Ag}-\mathrm{Ag}$ bonds form in both films. Hence, no evidence of $\mathrm{Ag}-$ $\mathrm{N}$ compound formation is found in the XPS data, despite the presence of $\mathrm{N}_{2}$ with a $p_{\mathrm{N} 2} / p_{\text {total }}$ ratio of $10 \%$ in the sputtering atmosphere. This is consistent with previous XPS studies by Depla and De Gryse. ${ }^{49}$ Moreover, N-1s high-resolution scans (not shown here) reveal traces of nitrogen $(\mathrm{N})$ in the $\mathrm{Ar} / \mathrm{N}_{2}$ grown sample: on the surface of the a-C/Ag/SiO ${ }_{2}$ stack $(\mathrm{C}-\mathrm{N}$, $\mathrm{C}=\mathrm{N}$, and $\mathrm{C} \equiv \mathrm{N}$ bonds) and in the vicinity of the $\mathrm{Ag} / \mathrm{SiO}_{2}$ interface ( $\mathrm{Si}-\mathrm{N}$ bonds). However, the XPS detection limit for $\mathrm{N}$ and other light elements is below 1 at. \%, while in our films the $\mathrm{N}-1 \mathrm{~s}$ peak cannot be easily resolved, since its binding energy coincides with the Ag-3d plasmon-loss satellite peak. ${ }^{49,65}$ Hence, ToF-SIMS measurements are performed to unequivocally confirm or refute $\mathrm{N}$ incorporation in the $\mathrm{Ag} / \mathrm{N}_{2}$ grown film, as explained in the following.

The ToF-SIMS technique exhibits sensitivity in the part-permillion range, but accurate quantitative concentration determination for dopants (i.e., low content elements as $\mathrm{N}$ in our case) is often nontrivial due to matrix effects related to different degrees of ionization for emitted secondary ions, while the use of reference samples is required. Hence, here we focus on qualitative analysis of the film composition. In our measurements, the most significant signals in negative ion spectra stem from $\mathrm{CN}^{-}$ions at $26 \mathrm{Da}$ - which we relate with $\mathrm{N}$ and are detected in both $\mathrm{Ar}$ and $\mathrm{Ar} / \mathrm{N}_{2}$-grown layers-and $\mathrm{Ag}^{-}$ ions at $107 \mathrm{Da}$. We attribute the presence of $\mathrm{N}$ in the sample deposited in pure Ar atmosphere to contamination from atmospheric exposure of (i) the substrate prior to film growth and (ii) the sample in the time between growth and SIMS measurements. Figure 6 plots the $\mathrm{CN}^{-}$-to- $\mathrm{Ag}^{-}$signal intensity ratio as a function of the sputtering depth (i.e., the product of

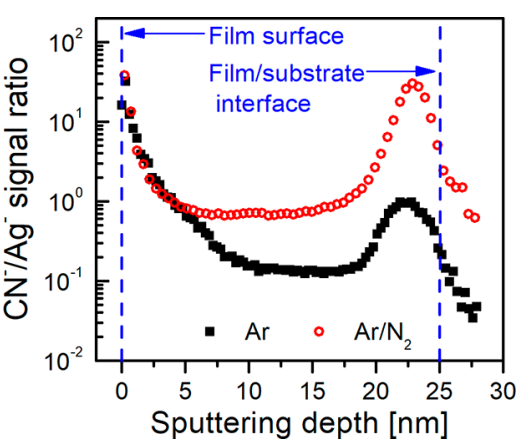

Figure 6. Ratio of $\mathrm{CN}^{-}$to $\mathrm{Ag}^{-}$ion signal vs sputtering depth as measured by ToF-SIMS for magnetron sputter-deposited Ag layers on $\mathrm{SiO}_{2} / \mathrm{Si}$ substrates in pure $\mathrm{Ar}$ (black squares) and $\mathrm{Ar} / \mathrm{N}_{2}$ (red circles) atmospheres. The position of the film surface and the approximate position of the film/substrate interface are indicated by dashed vertical lines.

the sputtering rate and the sputtering time) for Ag films grown in pure $\mathrm{Ar}$ (black squares) and mixed $\mathrm{Ar} / \mathrm{N}_{2}$ (red circles) atmospheres. The position of the film surface and the approximate position of the film/substrate interface (which corresponds to the film thickness of $25 \mathrm{~nm}$ according to the XRR results shown in section 3.3) are marked with blue dashed vertical lines. For both deposition conditions, the signal ratio exhibits a qualitatively similar evolution; i.e., it initially decreases when moving away from the surface into the bulk of the film and then shows a peak near the film/substrate interface. However, the $\mathrm{CN}^{-}$-to- $\mathrm{Ag}^{-}$signal ratio obtained for the $\mathrm{Ar} / \mathrm{N}_{2}$-grown film is systematically larger by up to 2 orders of magnitude than that for the Ar-deposited Ag layer, in the thickness range $10-25 \mathrm{~nm}$. This shows that presence of $\mathrm{N}_{2}$ in the growth atmosphere leads to incorporation $\mathrm{N}$ in the sample, primarily at the $\mathrm{Ag} / \mathrm{SiO}_{2}$ interface as indicated by the XPS results. The absence of $\mathrm{N}$ in the bulk of the Ag layer may be attributed to the weak $\mathrm{Ag}-\mathrm{N}$ interaction, which has been suggested to lead to $\mathrm{N}-\mathrm{N}$ recombination into $\mathrm{N}_{2}$ and desorption from the film surface. ${ }^{66,67}$ Accumulation of $\mathrm{N}$ at the film/substrate interface has also been reported by Yun et al. $^{44}$ for $\mathrm{Ag} / \mathrm{ZnO}$ heterostructures synthesized by magnetron sputtering in $\mathrm{Ar} / \mathrm{N}_{2}$ gas mixtures.

The occurrence of repeated nucleation in $\mathrm{Ag}$ films grown in mixed $\mathrm{Ar} / \mathrm{N}_{2}$ atmospheres is consistent with the fine-grained structure evidenced in the XRD and XTEM results in Figure S4 and Figure 5, respectively. This type of morphology can also explain the larger steady-state resistivity $\rho^{\text {ss }}$ for the $\mathrm{Ar} / \mathrm{N}_{2}$ - vs Ar-deposited films shown in Figure 1; a finer-grained structure implies a larger number density of grain boundaries, which scatter charge carriers and reduce their mean-free path. Repeated nucleation has been ascribed in the literature to intense energetic bombardment during growth and/or to surfactant and impurity adsorption at the film growth front. ${ }^{9,27}$ In our case, combined SIMS and XPS data support temporary $\mathrm{N}$ adsorption during $\mathrm{Ag}$ film growth in $\mathrm{Ar} / \mathrm{N}_{2}$ atmospheres, which may lead to interruption of local epitaxy and grain refinement. ${ }^{9,27,68}$

3.3. Growth Manipulation by Selective $\mathrm{N}_{2}$ Deployment. The results presented in sections 3.1 and 3.2 show that $\mathrm{N}_{2}$ has different effects on island nucleation, growth, and coalescence. These effects can be leveraged separately or combined to design versatile manipulation strategies for metalcontact fabrication in which $\mathrm{N}_{2}$ is introduced to the sputtering 
atmosphere with high temporal precision to selectively target film-growth stages and mechanisms. In this section we explore the viability of this approach by using the following $\mathrm{N}_{2}$ deployment schemes: (i) $\mathrm{N}_{2}$ is introduced at the early filmgrowth stages for $20 \mathrm{~s}$ (which corresponds to a value $\Theta \approx 8$ $\mathrm{ML}$ ) and, subsequently, is pumped out from the deposition chamber, while deposition continues and is completed in a pure $\mathrm{Ar}$ atmosphere. (ii) Deposition commences in a pure Ar atmosphere, and after $20 \mathrm{~s}$ (again $\Theta \approx 8 \mathrm{ML}$ ) $\mathrm{N}_{2}$ is introduced during the remainder of growth.

The effect of the two $\mathrm{N}_{2}$ deployment schemes on Ag-film morphological evolution is shown in Figure 7, which consists

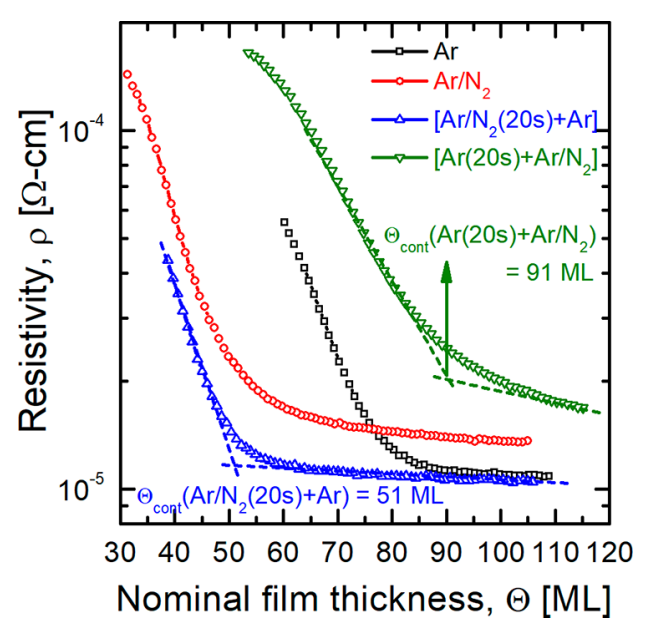

Figure 7. Resistivity $(\rho)$ vs nominal film thickness $(\Theta)$ curves, extracted from in situ, real-time spectroscopic ellipsometry measurements (see section 2.2), of magnetron sputter-deposited $\mathrm{Ag}$ films on $\mathrm{SiO}_{2} / \mathrm{Si}$ substrates in (i) an $\mathrm{Ar} / \mathrm{N}_{2}$ atmosphere for $20 \mathrm{~s}$ followed by growth in pure $\mathrm{Ar}$ (hollow blue triangles; denoted as $\left[\mathrm{Ar} / \mathrm{N}_{2}(20 \mathrm{~s})+\right.$ $\mathrm{Ar}]$ ) and (ii) an Ar atmosphere for $20 \mathrm{~s}$ followed by growth in $\mathrm{Ar} / \mathrm{N}_{2}$ (hollow inverse green triangles; denoted as $\left[\operatorname{Ar}(20 \mathrm{~s})+\operatorname{Ar} / \mathrm{N}_{2}\right]$ ). The $\rho$ vs $\Theta$ curves for the Ar-grown (hollow black squares) and $\mathrm{Ar} / \mathrm{N}_{2^{-}}$ grown (hollow read circles) films, originally presented in Figure 1, are reproduced for reference. The continuous film formation thicknesses $\Theta_{\text {cont }}$ for the $\left[\mathrm{Ar} / \mathrm{N}_{2}(20 \mathrm{~s})+\mathrm{Ar}\right]$ and the $\left[\operatorname{Ar}(20 \mathrm{~s})+\mathrm{Ar} / \mathrm{N}_{2}\right]$ samples are indicated in the figure.

of plots of film resistivity $\rho$ as a function of the nominal thickness $\Theta$ for the following conditions: (i) deposition in $\mathrm{Ar} /$ $\mathrm{N}_{2}$ atmosphere for $20 \mathrm{~s}$ followed by growth in $\mathrm{Ar}$ (blue triangles; denoted as $\left[\mathrm{Ar} / \mathrm{N}_{2}(20 \mathrm{~s})+\mathrm{Ar}\right]$ ) and (ii) deposition in pure $\mathrm{Ar}$ atmosphere for $20 \mathrm{~s}$ followed by growth in $\mathrm{Ar} / \mathrm{N}_{2}$ (inverse green triangles; denoted as $\left[\operatorname{Ar}(20 \mathrm{~s})+\operatorname{Ar} / \mathrm{N}_{2}\right]$ ). The $\rho$ vs $\Theta$ curves for the $\mathrm{Ar}$ - and $\mathrm{Ar} / \mathrm{N}_{2}$-grown films, originally plotted in Figure 1, are also reproduced in Figure 7 for reference.

The presence of $\mathrm{N}_{2}$ during the first $20 \mathrm{~s}$ of film deposition $\left(\left[\mathrm{Ar} / \mathrm{N}_{2}(20 \mathrm{~s})+\mathrm{Ar}\right]\right)$ yields a $\Theta_{\text {cont }}$ value equal to that of continuous growth in mixed $\mathrm{Ar} / \mathrm{N}_{2}$ atmospheres (=51 ML), i.e., $2 \mathrm{D}$ morphology is promoted, relative to the film grown in pure Ar for which $\Theta_{\text {cont }}=78 \mathrm{ML}$. This is explained considering the findings in Figure 2, where it is seen that $\mathrm{N}_{2}$ impedes coalescence completion, which happens primarily during the first $\approx 20 \mathrm{ML}$ of deposition. Concurrently, the Ag-layer conductivity is not compromised $\left(\rho^{\mathrm{ss}} \approx 1.1 \times 10^{-5} \Omega \cdot \mathrm{cm}\right)$, since $\mathrm{N}_{2}$ is not present during postcoalescence growth stages to cause substantial grain refinement.
Deployment of $\mathrm{N}_{2}$ after the first $20 \mathrm{~s}$ of deposition ( $[\operatorname{Ar}(20$ s) $\left.\left.+\mathrm{Ar} / \mathrm{N}_{2}\right]\right)$ results in $\Theta_{\text {cont }}=91 \mathrm{ML}$; i.e., a more pronounced 3D morphology is obtained compared to the Ar-deposited Ag layer. Moreover, the steady-state resistivity value increases to $\rho^{\text {ss }}=1.7 \times 10^{-5} \Omega \cdot \mathrm{cm}$, which is substantially larger in comparison to the values for both $\mathrm{Ar} / \mathrm{N}_{2}$-deposited $\left(\rho^{\mathrm{ss}} \approx 1.4\right.$ $\left.\times 10^{-5} \Omega \cdot \mathrm{cm}\right)$ and Ar-deposited $\left(\rho^{\mathrm{ss}}=1.1 \times 10^{-5} \Omega \cdot \mathrm{cm}\right)$ films. Under the $\left[\operatorname{Ar}(20 \mathrm{~s})+\operatorname{Ar} / \mathrm{N}_{2}\right]$ deposition scheme, $\mathrm{N}_{2}$ is deployed on a pronounced $3 \mathrm{D}$ film-growth front which has been formed by extensive and uninterrupted island coalescence during the early growth stages. The effect of $\mathrm{N}_{2}$ is then to interrupt local epitaxial growth and cause grain refinement on the rough postcoalescence film surface. This leads to higher resistivity than that for Ar-deposited samples. The fact that the film deposited under the $\left[\operatorname{Ar}(20 \mathrm{~s})+\operatorname{Ar} / \mathrm{N}_{2}\right]$ condition exhibits a larger $\Theta_{\text {cont }}$ value than the Ar-grown film indicates that interruption of epitaxial growth on a rough surface also impedes the hole-filling process and promotes further $3 \mathrm{D}$ growth.

To confirm the morphological trends observed in Figure 7, we perform ex situ XRR measurements on a-C/Ag/ $\mathrm{SiO}_{2} / \mathrm{Si}$ stacks in which the $\mathrm{Ag}$ layers were grown at the same conditions are those listed in Figure 7. Analysis of the reflectivity curves (Figure 8; black circles represent exper-

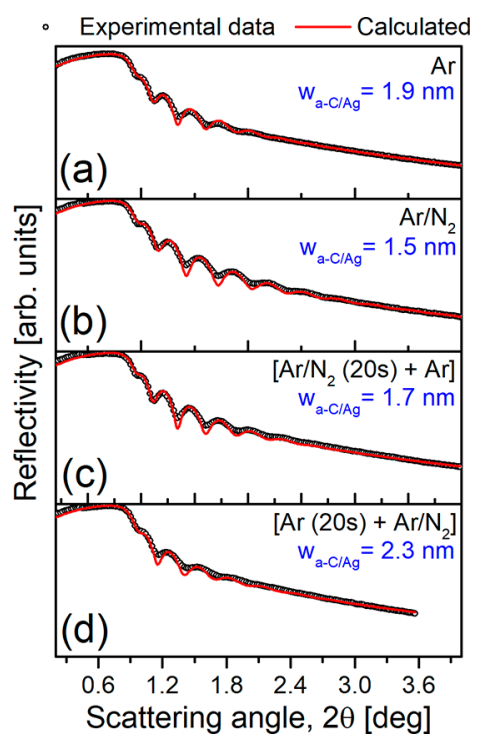

Figure 8. X-ray reflectivity curves (hollow black circles for experimental data and red solid lines for calculated curves) of a-C/ $\mathrm{Ag} / \mathrm{SiO}_{2} / \mathrm{Si}$ stacks in which $\mathrm{Ag}$ films are magnetron sputter-deposited in gas compositions: (a) $\mathrm{Ar}$; (b) $\mathrm{Ar} / \mathrm{N}_{2}$; (c) deposition in $\mathrm{Ar} / \mathrm{N}_{2}$ for $20 \mathrm{~s}$ followed by growth in $\mathrm{Ar}$ (denoted as $\left[\mathrm{Ar} / \mathrm{N}_{2}(20 \mathrm{~s})+\mathrm{Ar}\right]$ ); and (d) deposition in Ar atmosphere for $20 \mathrm{~s}$ followed by growth in $\mathrm{Ar} / \mathrm{N}_{2}$ (denoted as $\left[\operatorname{Ar}(20 \mathrm{~s})+\mathrm{Ar} / \mathrm{N}_{2}\right]$ ). The roughness of the a-C/Ag interface $w_{\mathrm{a}-\mathrm{C} / \mathrm{Ag}}$ is also provided for each case in the figure.

imental data and red solid lines represent calculated curves) shows that Ag films with thicknesses in the range $22-25 \mathrm{~nm}$ are deposited in all cases, which is in very good agreement with the thicknesses obtained from spectroscopic ellipsometry and XTEM. We also extract the roughness $w_{\mathrm{a}-\mathrm{C} / \mathrm{Ag}}$ of the a-C/Ag interface (i.e., the $\mathrm{Ag}$ film roughness) and find that the $\mathrm{Ar} /$

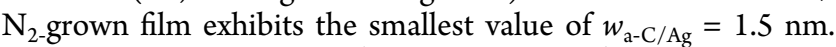
Slightly larger roughness $\left(w_{\mathrm{a}-\mathrm{C} / \mathrm{Ag}}=1.7 \mathrm{~nm}\right)$ is obtained for films grown at the condition $\left[\mathrm{Ar} / \mathrm{N}_{2}(20 \mathrm{~s})+\mathrm{Ar}\right]$, while $w_{\mathrm{a}-\mathrm{C} / \mathrm{Ag}}$ increases to $1.9 \mathrm{~nm}$ for the Ar-deposited sample. The largest 
value $w_{\mathrm{a}-\mathrm{C} / \mathrm{Ag}}=2.3 \mathrm{~nm}$ is obtained for the film synthesized under the condition $\left[\operatorname{Ar}(20 \mathrm{~s})+\mathrm{Ar} / \mathrm{N}_{2}\right]$. The XRR roughness data described above are consistent with the results from the $\rho$ vs $\Theta$ curves shown in Figure 7 ; i.e., early $\mathrm{N}_{2}$ deployment promotes $2 \mathrm{D}$ growth morphology, while the presence of $\mathrm{N}_{2}$ during postcoalescence growth stages yields roughness buildup at the film growth front. Moreover, we find that the mass density of the $\mathrm{Ag}$ layers is very close to the bulk value of $10.5 \mathrm{~g}$ $\mathrm{cm}^{-3}$ at all deposition conditions.

\section{CONCLUSION}

The ability to grow noble-metal films with two-dimensional (2D) morphologies on weakly interacting substrates, including 2D materials and oxides, is essential for the fabrication of highperformance enabling devices. The use of less-noble-metal and gaseous surfactants is a known strategy for manipulating the growth of noble metal layers, but the mechanisms by which surfactant atoms affect the complex structure-forming processes are not understood.

In the present work, we combine in situ film growth monitoring, ex situ characterization, and optical modeling in the framework of the finite-difference time-domain (FDTD) method to study the effect of nitrogen $\left(\mathrm{N}_{2}\right)$ gas surfactant on growth evolution of nanoscale silver $(\mathrm{Ag})$ islands and films on silicon dioxide $\left(\mathrm{SiO}_{2}\right)$ substrates, with the purpose of exploring the viability of surfactant-based approaches for metal-contact synthesis. We show that $\mathrm{N}_{2}$ presence during the early filmgrowth stages suppresses the rate of island coalescence, which favors 2D morphology and formation of flat films. Furthermore, for later growth stages beyond coalescence, $\mathrm{N}_{2}$ causes interruption of crystal growth, which leads to grain refinement and increases the resistivity of continuous layers. FDTD calculations confirm that monitoring of the localized surface plasmon resonance (LSPR) via spectroscopic ellipsometry can be a powerful tool to track and control in real time the early stage morphological evolution of ultrathin metal films and supported nanostructures on weakly interacting substrates.

Using the insights presented above, we design and implement growth manipulation experiments in which $\mathrm{N}_{2}$ is deployed selectively during specific growth stages. Early deployment only during the initial growth stages leads to decrease of coalescence rate and roughness development at the film growth front, without compromising the film electrical resistivity. On the contrary, postcoalescence $\mathrm{N}_{2}$ deployment leads to pronounced increase in film roughness. This knowledge opens the way for growth strategies in which surfactant species will be deployed with high temporal and spatial precision to target critical film formation stages and manipulate growth morphologies, without altering the film physical properties. Moreover, targeted surfactant deployment can be used to tune the size of supported 3D nanostructures without the need to employ elevated growth temperatures and postdeposition annealing steps.

\section{ASSOCIATED CONTENT}

\section{SI Supporting Information}

The Supporting Information is available free of charge at https://pubs.acs.org/doi/10.1021/acsanm.0c00736.

Description of the finite-difference time-domain method that was used to calculate the optical response of silver clusters; images and analysis of early stages of silver film growth obtained from plan-view transmission electron microscopy; determination of localized surface plasmon resonance position from computed total film reflectivity of periodic cluster spatial distributions; X-ray diffractograms and selected area electron diffractograms of continuous $\mathrm{Ar}$ - and $\mathrm{Ar} / \mathrm{N}_{2}$-grown silver films; X-ray photoemission spectra of $\mathrm{Ar}-$ and $\mathrm{Ar} / \mathrm{N}_{2}$-grown silver films (PDF)

\section{AUTHOR INFORMATION}

\section{Corresponding Author}

Kostas Sarakinos - Nanoscale Engineering Division, Department of Physics, Chemistry, and Biology, Linköping University, SE 58183 Linköping, Sweden; 이이.org/00000003-2864-9509; Email: kostas.sarakinos@liu.se

\section{Authors}

Andreas Jamnig - Nanoscale Engineering Division, Department of Physics, Chemistry, and Biology, Linköoping University, SE 58183 Linköping, Sweden; Institut Pprime, Département Physique et Mécanique des Materiaux, UPR 3346 CNRS, Universite de Poitiers, F86073 Cedex 9 Poitiers, France; (1) orcid.org/0000-0003-2765-2271

Nikolaos Pliatsikas - Nanoscale Engineering Division, Department of Physics, Chemistry, and Biology, Linköping University, SE 58183 Linköping, Sweden; 잉 orcid.org/00000002-5098-6950

Martin Konpan - Nanoscale Engineering Division, Department of Physics, Chemistry, and Biology, Linköping University, SE 58183 Linköping, Sweden

Jun Lu - Thin Film Physics Division, Department of Physics, Chemistry, and Biology, Linköping University, SE-581 83 Linköping, Sweden

Thomas Kehagias - Department of Physics, Aristotle University of Thessaloniki, GR-54124 Thessaloniki, Greece

Alexios N. Kotanidis - Department of Materials Science and Engineering, University of Ioannina, Ioannina 45110, Greece

Nikolaos Kalfagiannis - School of Science and Technology, Nottingham Trent University, NG11 8NS Nottingham, U.K.; (1) orcid.org/0000-0002-4030-5525

Dimitris V. Bellas - Department of Materials Science and Engineering, University of Ioannina, Ioannina 45110, Greece

Elefterios Lidorikis - Department of Materials Science and Engineering, University of Ioannina, Ioannina 45110, Greece; Institute of Materials Science and Computing, University Research Center of Ioannina (URCI), 45110 Ioannina, Greece; (1) orcid.org/0000-0002-9552-9366

Janez Kovac - Department of Surface Engineering and Optoelectronics, Jozef Stefan Institute, SI-1000 Ljubljana, Slovenia

Gregory Abadias - Institut Pprime, Département Physique et Mécanique des Materiaux, UPR 3346 CNRS, Université de Poitiers, F86073 Cedex 9 Poitiers, France; 잉 orcid.org/00000001-6801-9937

Ivan Petrov - Thin Film Physics Division, Department of Physics, Chemistry, and Biology, Linköping University, SE-581 83 Linköping, Sweden; Materials Science and Physics Departments, University of Illinois, Urbana, Illinois 61801, United States

Joseph E. Greene - Thin Film Physics Division, Department of Physics, Chemistry, and Biology, Linköping University, SE-581 83 Linköping, Sweden; Materials Science and Physics Departments, University of Illinois, Urbana, Illinois 61801, United States; Department of Materials Science and 
Engineering, National Taiwan University of Science and Technology, Taipei 10607, Taiwan

Complete contact information is available at: https://pubs.acs.org/10.1021/acsanm.0c00736

\section{Notes}

The authors declare no competing financial interest.

\section{ACKNOWLEDGMENTS}

A.J. and G.A. acknowledge the financial support of the French Government program "Investissements d'Avenir" (LABEX INTERACTIFS, reference ANR-11-LABX-0017-01). K.S. acknowledges financial support from Linköping University ("LiU Career Contract Dnr-LiU-2015-01510, 2015-2020") and the Swedish Research Council (Contract VR-201504630). A.J. and K.S. acknowledge financial support from the ÅForsk foundation (Contracts $\AA F$ 19-137 and $\AA F$ 19-746). K.S. and N.P. acknowledge financial support from the Olle Engkvist Foundation (Contract SOEB 190-312) and the Wenner-Gren Foundation (Contracts UPD2018-0071 and UPD2019-0007). J.K. acknowledges financial support from Slovenian Research Agency (Contract BI-US/18-20-08). T.K. acknowledges financial support by the project "INNOVATION-EL” (MIS 5002772), implemented under the Action "Reinforcement of the Research and Innovation Infrastructure", funded by the Operational Program "Competitiveness, Entrepreneurship and Innovation" (NSRF 2014-2020) and cofinanced by Greece and the European Union (European Regional Development Fund).

\section{REFERENCES}

(1) Echtermeyer, T. J.; Milana, S.; Sassi, U.; Eiden, A.; Wu, M.; Lidorikis, E.; Ferrari, A. C. Surface Plasmon Polariton Graphene Photodetectors. Nano Lett. 2016, 16 (1), 8-20.

(2) Mueller, T.; Xia, F.; Avouris, P. Graphene Photodetectors for High-Speed Optical Communications. Nat. Photonics 2010, 4 (5), 297-301.

(3) Xu, Y.; Hsieh, C.-Y.; Wu, L.; Ang, L. K. Two-Dimensional Transition Metal Dichalcogenides Mediated Long Range Surface Plasmon Resonance Biosensors. J. Phys. D: Appl. Phys. 2019, 52 (6), 065101.

(4) Liu, X.; Han, Y.; Evans, J. W.; Engstfeld, A. K.; Behm, R. J.; Tringides, M. C.; Hupalo, M.; Lin, H.-Q.; Huang, L.; Ho, K.-M.; Appy, D.; Thiel, P. A.; Wang, C.-Z. Growth Morphology and Properties of Metals on Graphene. Prog. Surf. Sci. 2015, 90 (4), 397443.

(5) Gong, C.; Huang, C.; Miller, J.; Cheng, L.; Hao, Y.; Cobden, D.; Kim, J.; Ruoff, R. S.; Wallace, R. M.; Cho, K.; Xu, X.; Chabal, Y. J. Metal Contacts on Physical Vapor Deposited Monolayer MoS2. ACS Nano 2013, 7 (12), 11350-11357.

(6) Campbell, C. T. Metal Films and Particles on Oxide Surfaces: Structural, Electronic and Chemisorptive Properties. J. Chem. Soc., Faraday Trans. 1996, 92 (9), 1435.

(7) Ohring, M. Materials Science of Thin Films; Academic Press: San Diego, 1991.

(8) Martin, P. M. Handbook of Deposition Technologies for Films and Coatings, 3rd ed.; Martin, P. M., Ed.; William Andrew: Amsterdam, 2010.

(9) Petrov, I.; Barna, P. B.; Hultman, L.; Greene, J. E. Microstructural Evolution during Film Growth. J. Vac. Sci. Technol., A 2003, 21 (5), S117-S128.

(10) Michely, T.; Krug, J. Islands, Mounds and Atoms; Springer Series in Surface Sciences 42; Springer: Berlin, 2004.
(11) Vrijmoeth, J.; van der Vegt, H. A.; Meyer, J. A.; Vlieg, E.; Behm, R. J. Surfactant-Induced Layer-by-Layer Growth of $\mathrm{Ag}$ on $\mathrm{Ag}(111)$ : Origins and Side Effects. Phys. Rev. Lett. 1994, 72 (24), 3843-3846.

(12) Oppo, S.; Fiorentini, V.; Scheffler, M. Theory of Adsorption and Surfactant Effect of Sb on $\mathrm{Ag}(111)$. Phys. Rev. Lett. 1993, 71 (15), 2437-2440.

(13) van der Vegt, H. A.; van Pinxteren, H. M.; Lohmeier, M.; Vlieg, E.; Thornton, J. M. C. Surfactant-Induced Layer-by-Layer Growth of $\mathrm{Ag}$ on $\mathrm{Ag}(111)$. Phys. Rev. Lett. 1992, 68 (22), 3335-3338.

(14) van der Vegt, H. A.; Breeman, M.; Ferrer, S.; Etgens, V. H.; Torrelles, X.; Fajardo, P.; Vlieg, E. Indium-Induced Lowering of the Schwoebel Barrier in the Homoepitaxial Growth of $\mathrm{Cu}(100)$. Phys. Rev. B: Condens. Matter Mater. Phys. 1995, 51 (20), 14806-14809.

(15) Breeman, M.; Barkema, G. T.; Langelaar, M. H.; Boerma, D. O. Computer Simulation of Metal-on-Metal Epitaxy. Thin Solid Films 1996, 272 (2), 195-207.

(16) van der Vegt, H. A.; Alvarez, J.; Torrelles, X.; Ferrer, S.; Vlieg, E. Indium-Induced Layer-by-Layer Growth and Suppression of Twin Formation in the Homoepitaxial Growth of $\mathrm{Cu}(111)$. Phys. Rev. B: Condens. Matter Mater. Phys. 1995, 52 (24), 17443-17448.

(17) Camarero, J.; Ferrón, J.; Cros, V.; Gómez, L.; Vázquez de Parga, A. L.; Gallego, J. M.; Prieto, J. E.; de Miguel, J. J.; Miranda, R. Atomistic Mechanism of Surfactant-Assisted Epitaxial Growth. Phys. Rev. Lett. 1998, 81 (4), 850-853.

(18) Esch, S.; Hohage, M.; Michely, T.; Comsa, G. Origin of Oxygen Induced Layer-by-Layer Growth in Homoepitaxy on $\mathrm{Pt}(111)$. Phys. Rev. Lett. 1994, 72 (4), 518-521.

(19) Poelsema, B.; Kunkel, R.; Nagel, N.; Becker, A. F.; Rosenfeld, G.; Verheij, L. K.; Comsa, G. New Phenomena in Homoepitaxial Growth of Metals. Appl. Phys. A: Solids Surf. 1991, 53 (5), 369-376.

(20) Hoegen, M. H.; Pietsch, H. Homoepitaxy of Si(111) Is Surface Defect Mediated. Surf. Sci. 1994, 321 (1-2), L129-L136.

(21) Voigtländer, B.; Zinner, A. Influence of Surfactants on the Growth-Kinetics of Si on Si(111). Surf. Sci. Lett. 1993, 292 (1-2), L775-L780.

(22) Horn-von Hoegen, M.; Falta, J.; Copel, M.; Tromp, R. M. Surfactants in Si(111) Homoepitaxy. Appl. Phys. Lett. 1995, 66 (4), 487-489.

(23) Kandel, D.; Kaxiras, E. The Surfactant Effect in Semiconductor Thin-Film Growth. In Solid State Physics; Ehrenreich, H., Spaepen, F., Eds.; Academic Press: New York, 2000; Vol. 54, pp 219-262.

(24) Camarero, J.; Graf, T.; de Miguel, J. J.; Miranda, R.; Kuch, W.; Zharnikov, M.; Dittschar, A.; Schneider, C. M.; Kirschner, J. Surfactant-Mediated Modification of the Magnetic Properties of $\mathrm{Co} / \mathrm{Cu}(111)$ Thin Films and Superlattices. Phys. Rev. Lett. 1996, 76 (23), 4428-4431.

(25) Scheuch, V.; Potthast, K.; Voigtländer, B.; Bonzel, H. P. Investigation of the Growth of $\mathrm{Co}$ on $\mathrm{Cu}(111)$ and $\mathrm{Sb} / \mathrm{Cu}(111)$ Using Photoelectron Forward Scattering. Surf. Sci. 1994, 318 (1-2), $115-128$.

(26) Wolter, H.; Schmidt, M.; Wandelt, K. Surfactant Induced Layer-by-Layer Growth of $\mathrm{Cu}$ on $\mathrm{Ru}(0001)$ as Revealed by Oscillatory Work Function Changes. Surf. Sci. 1993, 298 (1), 173186.

(27) Barna, P. B.; Adamik, M. Fundamental Structure Forming Phenomena of Polycrystalline Films and the Structure Zone Models. Thin Solid Films 1998, 317 (1-2), 27-33.

(28) Lü, B.; Almyras, G. A.; Gervilla, V.; Greene, J. E.; Sarakinos, K. Formation and Morphological Evolution of Self-Similar 3D Nanostructures on Weakly Interacting Substrates. Phys. Rev. Mater. 2018, 2 (6), 063401.

(29) Gervilla, V.; Almyras, G. A.; Thunström, F.; Greene, J. E.; Sarakinos, K. Dynamics of 3D-Island Growth on Weakly-Interacting Substrates. Appl. Surf. Sci. 2019, 488, 383-390.

(30) Sarakinos, K. A Review on Morphological Evolution of Thin Metal Films on Weakly-Interacting Substrates. Thin Solid Films 2019, 688, 137312 .

(31) Hershberger, M. T.; Hupalo, M.; Thiel, P. A.; Wang, C. Z.; Ho, K. M.; Tringides, M. C. Nonclassical "Explosive" Nucleation in $\mathrm{Pb}$ / 
Si(111) at Low Temperatures. Phys. Rev. Lett. 2014, 113 (23), 236101.

(32) Anders, A.; Byon, E.; Kim, D.-H.; Fukuda, K.; Lim, S. H. N. Smoothing of Ultrathin Silver Films by Transition Metal Seeding. Solid State Commun. 2006, 140 (5), 225-229.

(33) Gu, D.; Zhang, C.; Wu, Y. K.; Guo, L. J. Ultrasmooth and Thermally Stable Silver-Based Thin Films with Subnanometer Roughness by Aluminum Doping. ACS Nano 2014, 8 (10), 10343.

(34) Ciesielski, A.; Skowronski, L.; Górecka, E.; Kierdaszuk, J.; Szoplik, T. Growth Model and Structure Evolution of Ag Layers Deposited on Ge Films. Beilstein J. Nanotechnol. 2018, 9, 66-76.

(35) Liu, H.; Wang, B.; Leong, E. S. P.; Yang, P.; Zong, Y.; Si, G.; Teng, J.; Maier, S. A. Enhanced Surface Plasmon Resonance on a Smooth Silver Film with a Seed Growth Layer. ACS Nano 2010, 4 (6), 3139-3146.

(36) Furgeaud, C.; Simonot, L.; Michel, A.; Mastail, C.; Abadias, G. Impact of Ge Alloying on the Early Growth Stages, Microstructure and Stress Evolution of Sputter-Deposited Cu-Ge Thin Films. Acta Mater. 2018, 159, 286-295.

(37) Bulír, J.; Novotný, M.; Lynnykova, A.; Lančok, J.; Bodnár, M.; Škereň, M.; Martin-Palma, R. J.; Jen, Y.-J.; Lakhtakia, A. Preparation of Nanostructured Ultrathin Silver Layer. Proc. SPIE 2010, 77660Q.

(38) Zhao, G.; Wang, W.; Bae, T.-S.; Lee, S.-G.; Mun, C.; Lee, S.; Yu, H.; Lee, G.-H.; Song, M.; Yun, J. Stable Ultrathin Partially Oxidized Copper Film Electrode for Highly Efficient Flexible Solar Cells. Nat. Commun. 2015, 6 (1), 8830.

(39) Wang, W.; Song, M.; Bae, T.-S.; Park, Y. H.; Kang, Y.-C.; Lee, S.-G.; Kim, S.-Y.; Kim, D. H.; Lee, S.; Min, G.; Lee, G.-H.; Kang, J.W.; Yun, J. Transparent Ultrathin Oxygen-Doped Silver Electrodes for Flexible Organic Solar Cells. Adv. Funct. Mater. 2014, 24 (11), 15511561.

(40) Riveiro, J. M.; Normile, P. S.; Andrés, J. P.; González, J. A.; De Toro, J. A.; Muñoz, T.; Muñiz, P. Oxygen-Assisted Control of Surface Morphology in Nonepitaxial Sputter Growth of Ag. Appl. Phys. Lett. 2006, 89 (20), 201902.

(41) Birnbaum, A. J.; Thompson, C. V.; Steuben, J. C.; Iliopoulos, A. P.; Michopoulos, J. G. Oxygen-Induced Giant Grain Growth in Ag Films. Appl. Phys. Lett. 2017, 111 (16), 163107.

(42) Bulír, J.; Novotný, M.; Lančok, J.; Fekete, L.; Drahokoupil, J.; Musil, J. Nucleation of Ultrathin Silver Layer by Magnetron Sputtering in Ar/N2 Plasma. Surf. Coat. Technol. 2013, 228, S86-S90.

(43) Ko, R. H. H.; Khalatpour, A.; Clark, J. K. D.; Kherani, N. P. Ultrasmooth Ultrathin Ag Films by AlN Seeding and Ar/N 2 Sputtering for Transparent Conductive and Heating Applications. APL Mater. 2018, 6 (12), 121112.

(44) Yun, J.; Chung, H.-S.; Lee, S.-G.; Bae, J.-S.; Hong, T. E.; Takahashi, K.; Yu, S. M.; Park, J.; Guo, Q.; Lee, G.-H.; Han, S. Z.; Ikoma, Y.; Choi, E.-A. An Unexpected Surfactant Role of Immiscible Nitrogen in the Structural Development of Silver Nanoparticles: An Experimental and Numerical Investigation. Nanoscale 2020, 12 (3), $1749-1758$.

(45) Warrender, J. M.; Aziz, M. J. Effect of Deposition Rate on Morphology Evolution of Metal-on-Insulator Films Grown by Pulsed Laser Deposition. Phys. Rev. B: Condens. Matter Mater. Phys. 2007, 76 (4), 045414

(46) Oates, T. W. H.; Mücklich, A. Evolution of Plasmon Resonances during Plasma Deposition of Silver Nanoparticles. Nanotechnology 2005, 16 (11), 2606-2611.

(47) Jamnig, A.; Sangiovanni, D. G.; Abadias, G.; Sarakinos, K. Atomic-Scale Diffusion Rates during Growth of Thin Metal Films on Weakly-Interacting Substrates. Sci. Rep. 2019, 9 (1), 6640.

(48) Jamnig, A.; Pliatsikas, N.; Sarakinos, K.; Abadias, G. The Effect of Kinetics on Intrinsic Stress Generation and Evolution in SputterDeposited Films at Conditions of High Atomic Mobility. J. Appl. Phys. 2020, 127 (4), 045302.

(49) Depla, D.; De Gryse, R. Target Voltage Measurements during DC Sputtering of Silver in a Nitrogen/Argon Plasma. Vacuum 2003, 69 (4), 529-536.
(50) Lee, Y. S.; Heo, J.; Winkler, M. T.; Siah, S. C.; Kim, S. B.; Gordon, R. G.; Buonassisi, T. Nitrogen-Doped Cuprous Oxide as a pType Hole-Transporting Layer in Thin-Film Solar Cells. J. Mater. Chem. A 2013, 1 (48), 15416.

(51) Wang, Y.; Ghanbaja, J.; Horwat, D.; Yu, L.; Pierson, J. F. Nitrogen Chemical State in N-Doped Cu 2 O Thin Films. Appl. Phys. Lett. 2017, 110 (13), 131902.

(52) Herzinger, C. M.; Johs, B.; McGahan, W. A.; Woollam, J. A.; Paulson, W. Ellipsometric Determination of Optical Constants for Silicon and Thermally Grown Silicon Dioxide via a Multi-Sample, Multi-Wavelength, Multi-Angle Investigation. J. Appl. Phys. 1998, 83 (6), 3323-3336.

(53) Oates, T. W. H.; Wormeester, H.; Arwin, H. Characterization of Plasmonic Effects in Thin Films and Metamaterials Using Spectroscopic Ellipsometry. Prog. Surf. Sci. 2011, 86 (11-12), 328376.

(54) Wooten, F. Optical Properties of Solids; Academic Press: New York, 1972.

(55) Taflove, A.; Hagness, S. C. Computational Electrodynamics: The Finite-Difference Time-Domain Method, 3rd ed.; 2005.

(56) Lidorikis, E.; Egusa, S.; Joannopoulos, J. D. Effective Medium Properties and Photonic Crystal Superstructures of Metallic Nanoparticle Arrays. J. Appl. Phys. 2007, 101 (5), 054304.

(57) Elofsson, V.; Lü, B.; Magnfält, D.; Münger, E. P.; Sarakinos, K. Unravelling the Physical Mechanisms That Determine Microstructural Evolution of Ultrathin Volmer-Weber Films. J. Appl. Phys. 2014, 116 (4), 044302.

(58) Jensen, P. Growth of Nanostructures by Cluster Deposition: Experiments and Simple Models. Rev. Mod. Phys. 1999, 71 (5), 16951735.

(59) Carrey, J.; Maurice, J.-L. Transition from Droplet Growth to Percolation: Monte Carlo Simulations and an Analytical Model. Phys. Rev. B: Condens. Matter Mater. Phys. 2001, 63 (24), 245408.

(60) Carrey, J.; Maurice, J.-L. Scaling Laws near Percolation during Three-Dimensional Cluster Growth: A Monte Carlo Study. Phys. Rev. B: Condens. Matter Mater. Phys. 2002, 65 (20), 205401.

(61) Lü, B.; Münger, E. P.; Sarakinos, K. Coalescence-Controlled and Coalescence-Free Growth Regimes during Deposition of Pulsed Metal Vapor Fluxes on Insulating Surfaces. J. Appl. Phys. 2015, 117 (13), 134304.

(62) Kreibig, U.; Vollmer, M. Optical Properties of Metal Clusters; Springer Series in Materials Science; Springer: Berlin, 1995; Vol. 25.

(63) Scholl, J. A.; Koh, A. L.; Dionne, J. A. Quantum Plasmon Resonances of Individual Metallic Nanoparticles. Nature 2012, 483 (7390), 421-427.

(64) Iati, M. A.; Lidorikis, E.; Saija, R. Modeling of Enhanced Electromagnetic Fields in Plasmonic Nanostructures. In Handbook of Enhanced Spectroscopy; de la Chapelle, M. L., Gucciardi, P. G., LidgiGuigui, N., Eds.; Taylor \& Francis: Boca Raton, FL, 2016.

(65) Leiro, J.; Minni, E.; Suoninen, E. Study of Plasmon Structure in XPS Spectra of Silver and Gold. J. Phys. F: Met. Phys. 1983, 13 (1), $215-221$.

(66) Ueta, H.; Gleeson, M. A.; Kleyn, A. W. Scattering of Hyperthermal Nitrogen Atoms from the $\mathrm{Ag}(111)$ Surface $\dagger$. J. Phys. Chem. A 2009, 113 (52), 15092-15099.

(67) Carter, R. N.; Murphy, M. J.; Hodgson, A. On the Recombinative Desorption of N2 from $\operatorname{Ag}(111)$. Surf. Sci. 1997, $387(1-3), 102-111$.

(68) Hultman, L.; Bareño, J.; Flink, A.; Söderberg, H.; Larsson, K.; Petrova, V.; Odén, M.; Greene, J. E.; Petrov, I. Interface Structure in Superhard TiN-SiN Nanolaminates and Nanocomposites: Film Growth Experiments and $\mathrm{Ab}$ Initio Calculations. Phys. Rev. B: Condens. Matter Mater. Phys. 2007, 75 (15), 155437. 